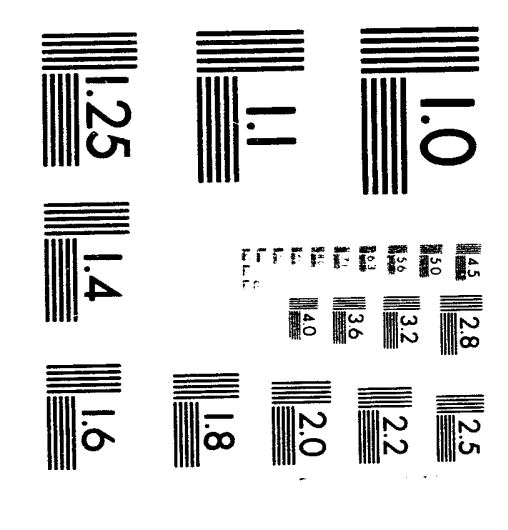

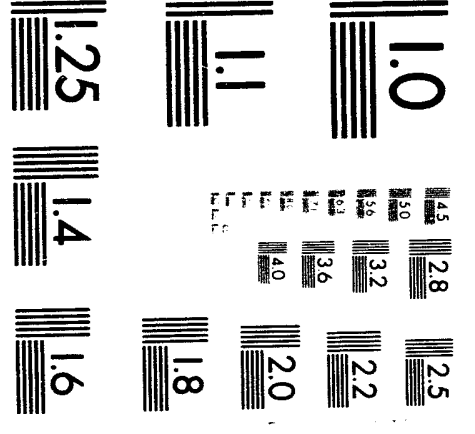

. 

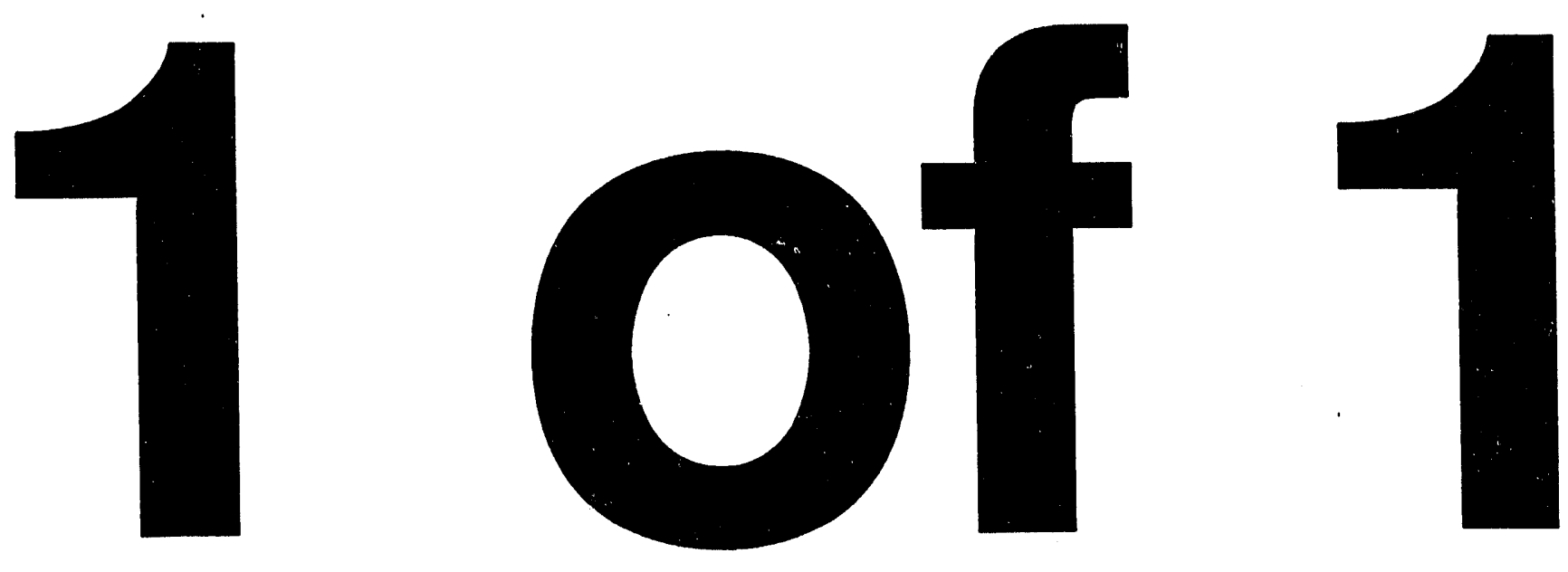


\section{Summary of FEA Calculations of STAR Support Rings*}

19 January 1994

Victor Guarino

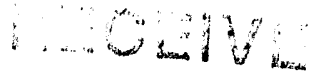

FEB 161994

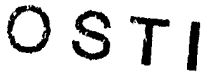

\section{Introduction}

Several FEA analyses of the STAR EM support rings have been performed. The original design was a continuous ring with a " $\mathrm{C}$ " channel cross section as shown in Figure 1. These rings were 2-3/4" thick with the center rings being only 1-3/4" thick. Based on the early analysis of these rings, it was determined that a continuous ring with a solid cross section should be used. This concept can be seen in Figure 2.

A thermal and mechanical analysis of both cross sections was performed. Because of symmetry, only half of the rings were modeled. The gravity load of the EM was applied to the ring by a rigid bar that extended radially from the location of the Thompson rails on the ring to the center of gravity of the EM module (see Figure 3).

In this paper we will first describe the analysis of the rings with the " $\mathrm{C}$ " channel cross section. The mechanical and thermal analysis of the thick 2-3/4" ring will be described, followed by the mechanical and thermal analysis of the thinner 1 $3 / 4$ " ring. In the second section, the analysis of the rings with the solid cross section will be described. Once again the thermal and mechanical analysis of the thicker 2$3 / 4$ " ring will be first followed by the description of the thinner $1-3 / 4$ " ring.

* Work supported by the U.S. Department of Energy, Division of High Energy Physics, Contract W-31-109-ENG-38.

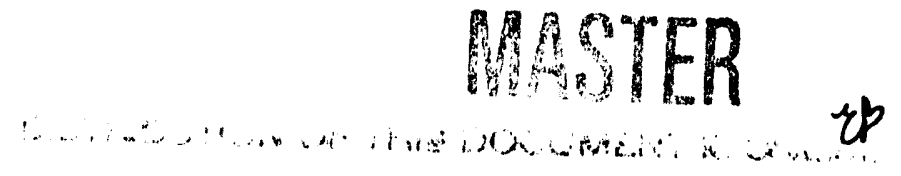




\section{Analysis of the "C" Cross Section Rings}

\section{$2-3 / 4^{\prime \prime}$ Rings}

The 2-3/4" thick rings were first analyzed. A mechanical analysis of the ring was performed in which only the loading from the EM modules, and the weight of the ring was applied. ${ }^{1}$ Next, the ring was analyzed using the additional thermal load imparted to the ring by an assumed $20^{\circ} \mathrm{Fahrenheit}$ temperature rise induced in the ring. 1

The initial mechanical analysis of the 2-3/4" rings found a maximum stress of 2,307 psi that occurs where the ring is supported at the bottom. The average stress throughout the ring is approximately $250 \mathrm{psi}$. The displacements of the ring, where the EMC modules are connected, are listed in Table 1 of the Appendix. Module number 1 is at the top of the ring at the 12 o'slock pesition and module number 30 is at the bottom of the ring in the $6 o^{\prime}$ clock position. Displacements are in the $\mathrm{Z}$ (beam) direction and in the vertical direction. The maximum $\mathrm{z}$ direction displacement was .007" and the maximum vertical displacement was only .001". The beam direction displacements change sign at the 3 o'clock position, which indicates that ring is twisting. This twist is due to the load from the module not being applied at the shear center of the ring cross section. The mechanical analysis was followed by a thermal analysis of the rings. It was assumed that the temperature of the rings will be raised by $20^{\circ}$ Fahrenheit. This temperature difference was chosen because it is the largest operating temperature range expected for the magnet. An FEA analysis, considering both the thermal and mechanical loading, was performed on the rings. The maximum stress was 12,175 psi. This stress occurs at the bottom support point on the rings. The majority of the ring has stresses of approximately 1,500 psi. The displacements are listed in Table 2 of the Appendix. Once again it can be seen that the ri $\mathrm{ig}$ is deflecting a significant amount (.023") in the beam direction. This gives a clear indication that the ring should be stiffened in order to eliminate twist, and that care should be taken to ensure that the loads are applied through the shear center of the cross section and not in line with the outside edge. Unlike the mechanical analysis in which the beam direction deflections changed signs, all of the beam direction deflections are in the positive direction. This is due to the flange in the inside diameter wanting to thermally expand outward. This expansion twists the web of the cross section and 
displaces it in the positive beam direction. The vertical deflections were small and did not exceed .004".

\section{Analysis of the Thinner 1-3/4" Ring}

Next an analysis of the thin ring in the center of the module was performed. First, a mechanical analysis of the ring was performed considering only the mechanical loading of the ring. The maximum stress in the ring was 2,305 psi that occurred at the bottom support point of the ring. The majority of the ring has stresses of approximately $400 \mathrm{psi}$. Table 3 in the Appendix lists the displacements of the 1-3/4" thick ring at the $\eta=0$ boundary. Once again the displacements in the vertical direction are small, approximately .001". However the displacements in the $\mathrm{Z}$ direction are as large as .009" and changes direction at the 3 o'clock position. This indicates that the ring is twisting due to it is not being loaded through the shear center of the cross section.

The thermal and mechanical analysis of the thinner 1-3/4" wide ring indicated that the maximum stress was $13,639 \mathrm{psi}$, and occurred at the points where the ring was supported. The average stress throughout the ring was approximately 2,300 psi. Table 4 in the Appendix lists the displacements of the ring. The maximum deflection in the beam direction was .012" and the maximum vertical deflection was only .003".

\section{Additional Analysis of "C" Channel Cross Section}

In order to compare different types of support an additional analysis was performed in which the thicker $23 / 4$ " thick ring was only supported at the top and bottom while keeping the mechanical loading the same. ${ }^{2}$ The maximum stress in the ring increased to 9,932 psi that occurred at the top and bottom support points. The average stress throughout the remainder of the ring was approximately 1,000 psi. The maximum deflection in the beam direction was .035" and the maximum vertical deflection was .056". The deflections of the ring are listed in Table 5 in the Appendix. 


\section{Analysis of the Solid Cross Section Continuous Ring}

Analysis of the 2-3/4" Thick Ring

An FEA analysis has been performed on the solid rectangular rings. Four separate analysis were performed: analysis of the thick $23 / 4$ " ring supported only at the top and bottom; ${ }^{3}$ analysis of the thick ring supported at 8 points; ${ }^{3}$ a thermal and mechanical analysis of the thick ring while supported at 8 points; ${ }^{3}$ and a thermal and mechanical analysis with a $50^{\circ}$ Fahrenheit temperature rise. This temperature range was chosen because it was the largest temperature range expected between the non-operating temperature in the winter and the maximum summer operating temperature.

The first model analyzed was the thick $23 / 4$ " ring when it is supported only at the top and bottom. The maximum stress was 4,744 psi that was concentrated at the support at the top and bottom. The average stress throughout the ring was approximately $700 \mathrm{psi}$. This analysis was done to compare it with previous analyses made by T. Fornek. It should be noted that Tom's model did not model the cross section and therefore cannot predict the concentrated stresses at the support. In addition it could not analyze the stresses in the ring due to the twisting of the ring that occurs because it is not loaded through the shear center. The maximum beam direction deflection was .009" and the maximum vertical deflection was .029". The deflections of the ring are listed in Table 6 of the Appendix.

The deflections in the vertical direction are quite large. The most disturbing deflections however are those in the $\mathrm{Z}$ direction. The inner radius of the ring moves cyclically inward and then outward which is an indication of buckling.

The thick ring was then analyzed when it was supported at 8 points. The maximum stress was $1,587 \mathrm{psi}$ and occurs at the support points. The average stress throughout the ring was approximately $300 \mathrm{psi}$. The maximum beam deflection was only .002" and the maximum vertical deflection was nearly zero at .0007". The deflections are listed in Table 7 of the Appendix.

The deflections are substantially smaller when the ring is supported at 8 points. The deflections in the $\mathrm{Z}$ directions are much smaller and only change sign once. The $\mathrm{Z}$ direction deflections in this case are due entirely to the load being 
applied off center. The change in sign of the $\mathrm{Z}$ deflections is caused simply by the change in direction of the applied load at different positions along the ring.

The next analysis performed on the thick ring was a thermal analysis in which the temperature rise was $20^{\circ}$ Fahrenheit. The maximum stress was 12,622 psi that occurs at the support at the bottom. The average stress throughout the ring was approximately $2,300 \mathrm{psi}$. The maximum deflection in the beam direction was .003" and the maximum vertical deflection was .004". The deflections of the ring are listed in Table 8 of the Appendix.

As a check of the FEA model, the element mesh of the thick ring was doubled. The same thermal and mechanical analysis was then performed. The deflections of the ring were identical, however the concentrated stresses at the bottom support increased to $15,000 \mathrm{psi}$. This would indicate that the basic model is accurate, however the concentrated stresses that occur at the support points are difficult to predict because of the difficulty in accurately modeling the connection.

The final analysis of the thick solid cross section is a thermal analysis in which the temperature of the rings is raised $50^{\circ}$ Fahrenheit. The maximum stress in the ring increased significantly to $29,075 \mathrm{psi}$ that occurred at the bottom support point. The maximum deflection in the beam direction was $.004 "$ and the maximum deflection in the vertical direction was .008 " which are still insignificant. The deflections are listed in Table 9 in the Appendix.

Analysis of Thin 1-3/4" Ring

A thermal analysis was performed on the thinner center rings. ${ }^{3}$ A $20^{\circ}$ Fahrenheit temperature rise was assumed and the ring was supported at 8 points. The maximum stress was $13,399 \mathrm{psi}$ at the bottom support. The maximum deflection in the beam direction was .006" and the maximum deflection in the vertical direction was only .003". The deflections of the ring are listed in Table 10 in the Appendix.

An additional thermal analysis was performed in which the temperature of the ring was raised $50^{\circ}$ Fahrenheit. The maximum stress was 30,152 psi that occurred at the bottom support. The average stress throughout the ring was approximately $6,000 \mathrm{psi}$. The maximum deflection in the beam direction was $.006 "$ 
and the maximum deflection in the vertical direction was $.008 "$. The deflection of the ring are listed in Table 11 in the Appendix.

The deflections of the ring when the temperature is raised $20^{\circ}$ and $50^{\circ}$ are very similar because the ring is supported the same was in both models and is restrained from moving in the radial direction.

\section{Conclusion}

It is clear that the initial design of a continuous ring with a " $C$ " cross section cannot meet the stress and deflection requirements of the EM calorimeter. The continuous ring with a solid cross section is much stiffer, however the stresses from thermal loading are still very high. There are three ways to eliminate the high thermal stresses: segment the ring; allow the continuous rings to expand radially; and reduce the operating temperature range of the coils.

\section{References}

1) "FEA Calculations of STAR Support Rings", V. Guarino in memo to H. Spinka et al., 07 December 1993.

2) "FEA Calculations of STAR Support Rings, V. Guarino in memo to H. Spinka et al., 16 December 1993.

3) "FEA Analysis of Solid Rings, V. Guarino in memo to D. Underwood et al., 20 December 1993. 


\section{APPENDIX}

Table 1

"C" Channel Cross Section Mechanical Analysis

Displacement of 2-3/4" Wide Ring -. Supported at 8 Points

\begin{tabular}{|c|c|c|}
\hline Module \# & $\begin{array}{l}\text { Z Displacement } \\
\text { (in.) }\end{array}$ & $\begin{array}{l}\text { Vertical Displacement } \\
\text { (in.) }\end{array}$ \\
\hline 1 & .007 & -.0008 \\
\hline 2 & .007 & -.0009 \\
\hline 3 & .006 & -.001 \\
\hline 4 & .006 & -.001 \\
\hline 5 & .006 & -.001 \\
\hline 6 & .006 & -.0007 \\
\hline 7 & .006 & -.0007 \\
\hline 8 & .005 & -.0007 \\
\hline 9 & .005 & -.0005 \\
\hline 10 & .005 & -.0003 \\
\hline 11 & .004 & -.0003 \\
\hline 12 & .003 & -.0002 \\
\hline 13 & .002 & -.0003 \\
\hline 14 & .001 & -.0001 \\
\hline 15 & .0006 & 0 \\
\hline 16 & -.0005 & 0 \\
\hline 17 & -.001 & -.0001 \\
\hline 18 & -.002 & -.0003 \\
\hline 19 & -.002 & -.0002 \\
\hline 20 & -.003 & -.0003 \\
\hline 21 & -.004 & -.0002 \\
\hline 22 & -.005 & -.0003 \\
\hline 23 & -.005 & -.0005 \\
\hline 24 & -.006 & -.0006 \\
\hline 25 & -.006 & -.0007 \\
\hline 26 & -.006 & -.0009 \\
\hline 27 & -.006 & -.001 \\
\hline 28 & -.006 & -.001 \\
\hline 29 & -.006 & -.0009 \\
\hline 30 & -.006 & -.0008 \\
\hline
\end{tabular}




\section{Table 2}

"C" Channel Cross Section Thermal and Mechanical Analysis

Displacement of 2-3/4" Wide Ring -. Supported at 8 Points $20^{\circ}$ Temperature Rise

\begin{tabular}{|c|c|c|}
\hline Module \# & $\begin{array}{l}\text { Z Displacement } \\
\text { (in.) }\end{array}$ & $\begin{array}{c}\begin{array}{c}\text { Vertical Displacement } \\
\text { (in.) }\end{array} \\
\end{array}$ \\
\hline 1 & .0148 & -.004 \\
\hline 2 & .0182 & -.003 \\
\hline 3 & .023 & -.001 \\
\hline 4 & .0229 & -.0008 \\
\hline 5 & .0187 & -.002 \\
\hline 6 & .018 & -.0025 \\
\hline 7 & .022 & -.001 \\
\hline 8 & .021 & -.0002 \\
\hline 9 & .017 & -.001 \\
\hline 10 & .016 & -.001 \\
\hline 11 & .020 & -.0008 \\
\hline 12 & .019 & .0003 \\
\hline 13 & .014 & 0 \\
\hline 14 & .013 & -.001 \\
\hline 15 & .016 & -.0005 \\
\hline 16 & .015 & .0005 \\
\hline 17 & .010 & .0008 \\
\hline 18 & .010 & -.0006 \\
\hline 19 & .013 & -.0007 \\
\hline 20 & .013 & .0001 \\
\hline 21 & .007 & .001 \\
\hline 22 & .006 & .0001 \\
\hline 23 & .010 & -.001 \\
\hline 24 & .009 & -.0003 \\
\hline 25 & .005 & .001 \\
\hline 26 & .005 & .0001 \\
\hline 27 & .009 & -.001 \\
\hline 28 & .009 & -.001 \\
\hline 29 & .004 & .001 \\
\hline 30 & .001 & .002 \\
\hline
\end{tabular}




\section{Table 3}

\section{"C" Channel Cross Section Mechanical Analysis}

\section{Displacement of 1-3/4" Wide Ring -- Supported at 8 Points}

\begin{tabular}{|c|c|c|}
\hline Module \# & $\begin{array}{l}\text { Z Displacement } \\
\text { (in.) }\end{array}$ & $\begin{array}{l}\text { Vertical Displacement } \\
\text { (in.) }\end{array}$ \\
\hline 1 & .009 & -.001 \\
\hline 2 & .009 & -.001 \\
\hline 3 & .009 & -.001 \\
\hline 4 & .009 & -.001 \\
\hline 5 & .009 & -.001 \\
\hline 6 & .009 & -.0009 \\
\hline 7 & .008 & -.0009 \\
\hline 8 & .007 & -.0008 \\
\hline 9 & .006 & -.0007 \\
\hline 10 & .006 & -.0005 \\
\hline 11 & .005 & -.0005 \\
\hline 12 & .004 & -.0004 \\
\hline 13 & .003 & -.0001 \\
\hline 14 & .002 & -.0002 \\
\hline 15 & .0007 & -.0001 \\
\hline 16 & -.0005 & -.0004 \\
\hline 17 & -.0001 & -.0002 \\
\hline 18 & -.002 & -.0001 \\
\hline 19 & -.004 & -.0002 \\
\hline 20 & -.009 & -.0003 \\
\hline 21 & -.009 & -.0004 \\
\hline 22 & -.009 & -.0006 \\
\hline 23 & -.009 & -.0008 \\
\hline 24 & -.009 & -.0009 \\
\hline 25 & -.009 & -.0009 \\
\hline 26 & -.009 & -.001 \\
\hline 27 & -.009 & -.001 \\
\hline 28 & -.009 & -.001 \\
\hline 29 & .009 & -.001 \\
\hline 30 & -.009 & -.0009 \\
\hline
\end{tabular}




\section{Table 4}

\section{"C" Channel Cross Section Thermal and Mechanical Analysis}

Displacement of 1-3/4" Wide Ring -. Supported at 8 Points $20^{\circ}$ Temperature Rise

\begin{tabular}{|c|c|c|}
\hline Module \# & $\begin{array}{c}\text { Z Displacement } \\
\text { (in.) }\end{array}$ & $\begin{array}{l}\text { Vertical Displacement } \\
\text { (in.) }\end{array}$ \\
\hline 1 & .006 & -.003 \\
\hline 2 & .008 & -.002 \\
\hline 3 & .011 & -.0009 \\
\hline 4 & .011 & -.0005 \\
\hline 5 & .007 & -.001 \\
\hline 6 & .007 & -.002 \\
\hline 7 & .009 & -.0007 \\
\hline 8 & .008 & 0 \\
\hline 9 & .004 & -.0007 \\
\hline 10 & .004 & -.001 \\
\hline 11 & .006 & -.0006 \\
\hline 12 & .005 & -.0002 \\
\hline 13 & .001 & -.0002 \\
\hline 14 & .0002 & -.001 \\
\hline 15 & .001 & -.0005 \\
\hline 16 & .0004 & .0003 \\
\hline 17 & -.003 & .0005 \\
\hline 18 & -.005 & -.0005 \\
\hline 19 & -.003 & -.0008 \\
\hline 20 & -.004 & -.0002 \\
\hline 21 & -.009 & -.0006 \\
\hline 22 & -.009 & -.0005 \\
\hline 23 & -.007 & -.001 \\
\hline 24 & -.008 & -.001 \\
\hline 25 & -.011 & -.0001 \\
\hline 26 & -.011 & -.0007 \\
\hline 27 & -.007 & -.001 \\
\hline 28 & -.007 & -.001 \\
\hline 29 & -.010 & -.0003 \\
\hline 30 & -.012 & -.0001 \\
\hline
\end{tabular}




\section{Table 5}

Mechanical Loading of "C" Section Ring

\section{Displacement of 2-3/4" Wide Ring -- Supported at 2 Points}

\begin{tabular}{|c|c|c|}
\hline Module \# & $\begin{array}{l}\text { Z Displacement } \\
\text { (in.) }\end{array}$ & $\begin{array}{c}\begin{array}{l}\text { Vertical Displacement } \\
\text { (in.) }\end{array} \\
\end{array}$ \\
\hline 1 & .027 & -.004 \\
\hline 2 & .022 & -.008 \\
\hline 3 & .015 & -.016 \\
\hline 4 & .007 & -.024 \\
\hline 5 & .0007 & -.032 \\
\hline 6 & -.005 & -.040 \\
\hline 7 & -.009 & -.046 \\
\hline 8 & -.012 & -.051 \\
\hline 9 & -.012 & -.054 \\
\hline 10 & -.011 & -.056 \\
\hline 11 & -.009 & -.056 \\
\hline 12 & -.005 & -.056 \\
\hline 13 & .0002 & -.055 \\
\hline 14 & .006 & -.054 \\
\hline 15 & .013 & -.054 \\
\hline 16 & .019 & -.054 \\
\hline 17 & .025 & -.054 \\
\hline 18 & .030 & -.055 \\
\hline 19 & .034 & -.055 \\
\hline 20 & .035 & -.056 \\
\hline 21 & .034 & -.055 \\
\hline 22 & .031 & -.053 \\
\hline 23 & .026 & -.050 \\
\hline 24 & .020 & -.045 \\
\hline 25 & .013 & -.039 \\
\hline 26 & .004 & -.031 \\
\hline 27 & -.004 & -.023 \\
\hline 28 & -.013 & -.015 \\
\hline 29 & -.020 & -.008 \\
\hline 30 & -.026 & -.003 \\
\hline
\end{tabular}




\section{Table 6}

\section{Solid Cross Section}

Deflections of the Thick 2-3/4" Wide Ring -- Supported at Top and Bottom

\begin{tabular}{|c|c|c|}
\hline Module \# & $\begin{array}{c}\mathrm{Z} \text { Displacement } \\
\text { (in.) }\end{array}$ & $\begin{array}{l}\text { Vertical Displacement } \\
\text { (in.) }\end{array}$ \\
\hline 1 & .007 & -.001 \\
\hline 2 & .006 & -.004 \\
\hline 3 & .004 & -.007 \\
\hline 4 & .001 & -.012 \\
\hline 5 & -.0008 & -.016 \\
\hline 6 & -.003 & -.020 \\
\hline 7 & -.005 & -.024 \\
\hline 8 & -.007 & -.026 \\
\hline 9 & -.009 & -.028 \\
\hline 10 & -.009 & -.029 \\
\hline 11 & -.009 & -.029 \\
\hline 12 & -.008 & -.029 \\
\hline 13 & -.007 & -.029 \\
\hline 14 & -.005 & -.029 \\
\hline 15 & -.003 & -.028 \\
\hline 16 & -.001 & -.028 \\
\hline 17 & 0 & -.028 \\
\hline 18 & .001 & -.029 \\
\hline 19 & .003 & -.029 \\
\hline 20 & .004 & -.029 \\
\hline 21 & .005 & -.029 \\
\hline 22 & .005 & -.028 \\
\hline 23 & .004 & -.026 \\
\hline 24 & .003 & -.024 \\
\hline 25 & .001 & -.020 \\
\hline 26 & -.0004 & -.016 \\
\hline 27 & -.002 & -.012 \\
\hline 28 & -.004 & -.008 \\
\hline 29 & -.006 & -.004 \\
\hline 30 & -.007 & -.002 \\
\hline
\end{tabular}




\section{Table 7}

\section{Solid Cross Section}

Deflections of the Thick 2-3/4" Wide Ring -- Supported at 8 Points

\begin{tabular}{|c|c|c|}
\hline Module \# & $\begin{array}{l}\text { Z Displacement } \\
\text { (in.) }\end{array}$ & $\begin{array}{l}\text { Vertical Displacement } \\
\text { (in.) }\end{array}$ \\
\hline 1 & .002 & -.0005 \\
\hline 2 & .002 & -.0005 \\
\hline 3 & .002 & -.0007 \\
\hline 4 & .002 & -.0007 \\
\hline 5 & .002 & -.0007 \\
\hline 6 & .002 & -.0006 \\
\hline 7 & .002 & -.0005 \\
\hline 8 & .002 & -.0005 \\
\hline 9 & .002 & -.0004 \\
\hline 10 & .002 & -.0003 \\
\hline 11 & .001 & -.0002 \\
\hline 12 & .001 & -.0002 \\
\hline 13 & .001 & 0 \\
\hline 14 & .0009 & -.0001 \\
\hline 15 & .0006 & -.0001 \\
\hline 16 & .0003 & 0 \\
\hline 17 & -.0001 & 0 \\
\hline 18 & -0.006 & 0 \\
\hline 19 & -.001 & -.0001 \\
\hline 20 & -.001 & -.0001 \\
\hline 21 & -.001 & -.0002 \\
\hline 22 & -.001 & -.0002 \\
\hline 23 & -.002 & -.0003 \\
\hline 24 & -.002 & -.0004 \\
\hline 25 & -.002 & -.0005 \\
\hline 26 & -.002 & -.0005 \\
\hline 27 & -.002 & -.0006 \\
\hline 28 & -.002 & -.0007 \\
\hline 29 & -.002 & -.0007 \\
\hline 30 & -.002 & -.0005 \\
\hline
\end{tabular}




\section{Table 8}

\section{Solid Cross Section}

\section{Deflections of the Thick 2-3/4" Wide Ring -. Supported at 8 Points}

$20^{\circ}$ Temperature Rise

\begin{tabular}{|c|c|c|}
\hline Module \# & $\begin{array}{l}\text { Z Displacement } \\
\text { (in.) }\end{array}$ & $\begin{array}{l}\text { Vertical Displacement } \\
\text { (in.) }\end{array}$ \\
\hline$\overline{1}$ & .001 & -.004 \\
\hline 2 & .002 & -.002 \\
\hline 3 & .002 & -.0008 \\
\hline 4 & .002 & -.0003 \\
\hline 5 & .002 & -.001 \\
\hline 6 & .002 & -.002 \\
\hline 7 & .002 & -.0006 \\
\hline 8 & .001 & 0 \\
\hline 9 & .001 & -.0007 \\
\hline 10 & .001 & -.001 \\
\hline 11 & .001 & -.0006 \\
\hline 12 & .0009 & -.0004 \\
\hline 13 & .0005 & .0001 \\
\hline 14 & .0002 & -.0009 \\
\hline 15 & -.0001 & -.0005 \\
\hline 16 & -.0006 & .0005 \\
\hline 17 & -.001 & .0008 \\
\hline 18 & -.001 & -.0003 \\
\hline 19 & -.001 & -.0006 \\
\hline 20 & -.002 & .0001 \\
\hline 21 & -.002 & .001 \\
\hline 22 & -.002 & 0 \\
\hline 23 & -.002 & -.0009 \\
\hline 24 & -.003 & -.0003 \\
\hline 25 & -.003 & .0009 \\
\hline 26 & -.003 & .0002 \\
\hline 27 & -.003 & -.001 \\
\hline 28 & -.003 & -.0007 \\
\hline 29 & -.003 & .001 \\
\hline 30 & -.003 & .002 \\
\hline
\end{tabular}




\section{Table 9}

Solid Cross Section

Deflections of the Thick 2-3/4" Wide Ring -- Supported at 8 Points
$50^{\circ}$ Temperature Rise

\begin{tabular}{|c|c|c|}
\hline Module \# & $\begin{array}{l}\text { Z Displacement } \\
\text { (in.) }\end{array}$ & $\begin{array}{l}\text { Vertical Displacement } \\
\text { (in.) }\end{array}$ \\
\hline 1 & .002 & -.008 \\
\hline 2 & .002 & -.005 \\
\hline 3 & .001 & -.0008 \\
\hline 4 & .001 & .0002 \\
\hline 5 & .002 & -.002 \\
\hline 6 & .001 & -.004 \\
\hline 7 & .001 & -.001 \\
\hline 8 & .001 & .0006 \\
\hline 9 & .001 & -.001 \\
\hline 10 & .0009 & -.003 \\
\hline 11 & .0005 & -.001 \\
\hline 12 & .0002 & .001 \\
\hline 13 & 0 & .0004 \\
\hline 14 & -.0003 & -.002 \\
\hline 15 & -.0008 & -.001 \\
\hline 16 & -.001 & .001 \\
\hline 17 & -.001 & .002 \\
\hline 18 & -.002 & -.0007 \\
\hline 19 & -.002 & -.001 \\
\hline 20 & -.003 & .0007 \\
\hline 21 & -.003 & .002 \\
\hline 22 & -.003 & .0006 \\
\hline 23 & -.003 & -.001 \\
\hline 24 & -.004 & 0 \\
\hline 25 & -.003 & .003 \\
\hline 26 & -.004 & .001 \\
\hline 27 & -.004 & -.001 \\
\hline 28 & -.004 & -.0007 \\
\hline 29 & -.004 & .004 \\
\hline 30 & -.004 & .007 \\
\hline
\end{tabular}




\section{Table 10}

Solid Cross Section Thermal and Mechanical Analysis

Deflections of the Thick 1-3/4" Ring -- Supported at 8 Points $20^{\circ}$ Temperature Rise

\begin{tabular}{|c|c|c|}
\hline Module \# & $\begin{array}{l}\text { Z Displacement } \\
\text { (in.) }\end{array}$ & $\begin{array}{l}\text { Vertical Displacement } \\
\text { (in.) }\end{array}$ \\
\hline 1 & .005 & -.003 \\
\hline 2 & .005 & -.002 \\
\hline 3 & .005 & -.001 \\
\hline 4 & .005 & -.0008 \\
\hline 5 & .005 & -.001 \\
\hline 6 & .005 & -.002 \\
\hline 7 & .005 & -.001 \\
\hline 8 & .004 & .0004 \\
\hline 9 & .004 & -.001 \\
\hline 10 & .003 & -.001 \\
\hline 11 & .002 & -.0009 \\
\hline 12 & .002 & 0 \\
\hline 13 & .001 & -.0003 \\
\hline 14 & .0008 & -.001 \\
\hline 15 & 0 & -.0009 \\
\hline 16 & -.0006 & 0 \\
\hline 17 & -.001 & .0003 \\
\hline 18 & -.002 & -.0008 \\
\hline 19 & -.002 & -.001 \\
\hline 20 & -.003 & -.0002 \\
\hline 21 & -.004 & .0006 \\
\hline 22 & -.004 & -.0004 \\
\hline 23 & -.005 & -.001 \\
\hline 24 & -.005 & -.0007 \\
\hline 25 & -.006 & .0008 \\
\hline 26 & -.006 & -.0001 \\
\hline 27 & -.006 & -.001 \\
\hline 28 & -.006 & -.001 \\
\hline 29 & -.006 & .0009 \\
\hline 30 & -.006 & .002 \\
\hline
\end{tabular}




\section{Table 11}

Solid Cross Section Thermal and Mechanical Analysis

\section{Deflections of the Thick 1-3/4" Ring -- Supported at 8 Points} $50^{\circ}$ Temperature Rise

\begin{tabular}{|c|c|c|}
\hline Module \# & $\begin{array}{l}\text { Z Displacement } \\
\text { (in.) }\end{array}$ & $\begin{array}{l}\text { Vertical Displacement } \\
\text { (in.) }\end{array}$ \\
\hline 1 & .005 & -.008 \\
\hline 2 & .005 & -.005 \\
\hline 3 & .005 & -.001 \\
\hline 4 & .005 & -.0001 \\
\hline 5 & .005 & -.003 \\
\hline 6 & .005 & -.004 \\
\hline 7 & .004 & -.001 \\
\hline 8 & .004 & .0002 \\
\hline 9 & .003 & -.001 \\
\hline 10 & .003 & -.003 \\
\hline 11 & .002 & -.001 \\
\hline 12 & .001 & .0006 \\
\hline 13 & .001 & 0 \\
\hline 14 & .0004 & -.002 \\
\hline 15 & -.0004 & -.003 \\
\hline 16 & -.001 & .0007 \\
\hline 17 & -.001 & .001 \\
\hline 18 & -.002 & -.001 \\
\hline 19 & -.003 & -.001 \\
\hline 20 & -.003 & .0003 \\
\hline 21 & -.004 & .002 \\
\hline 22 & -.005 & .0001 \\
\hline 23 & -.005 & -.002 \\
\hline 24 & -.006 & -.0004 \\
\hline 25 & -.006 & .002 \\
\hline 26 & -.006 & .001 \\
\hline 27 & -.006 & .002 \\
\hline 28 & -.006 & -.001 \\
\hline 29 & -.006 & .003 \\
\hline 30 & -.006 & .006 \\
\hline
\end{tabular}




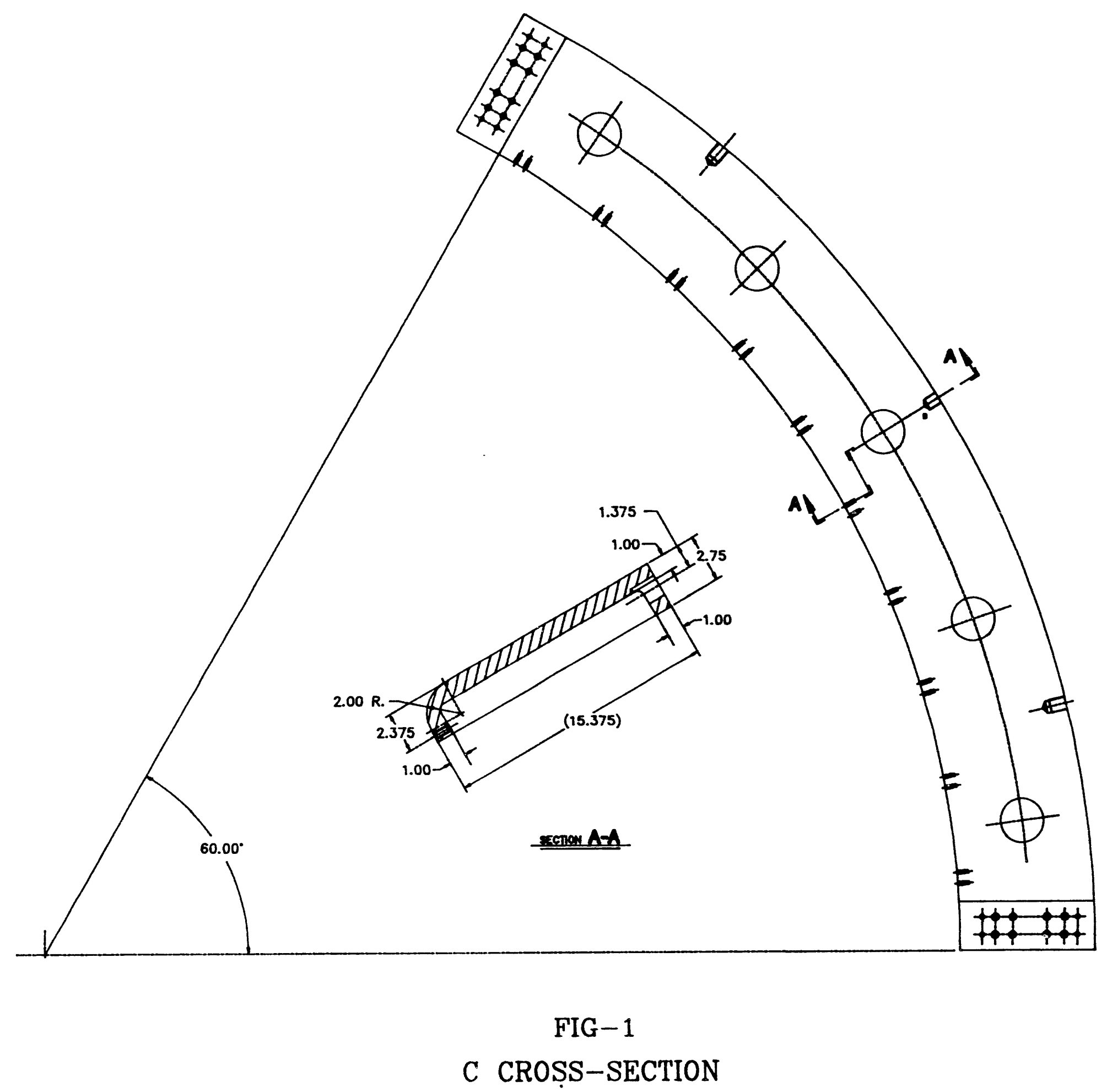




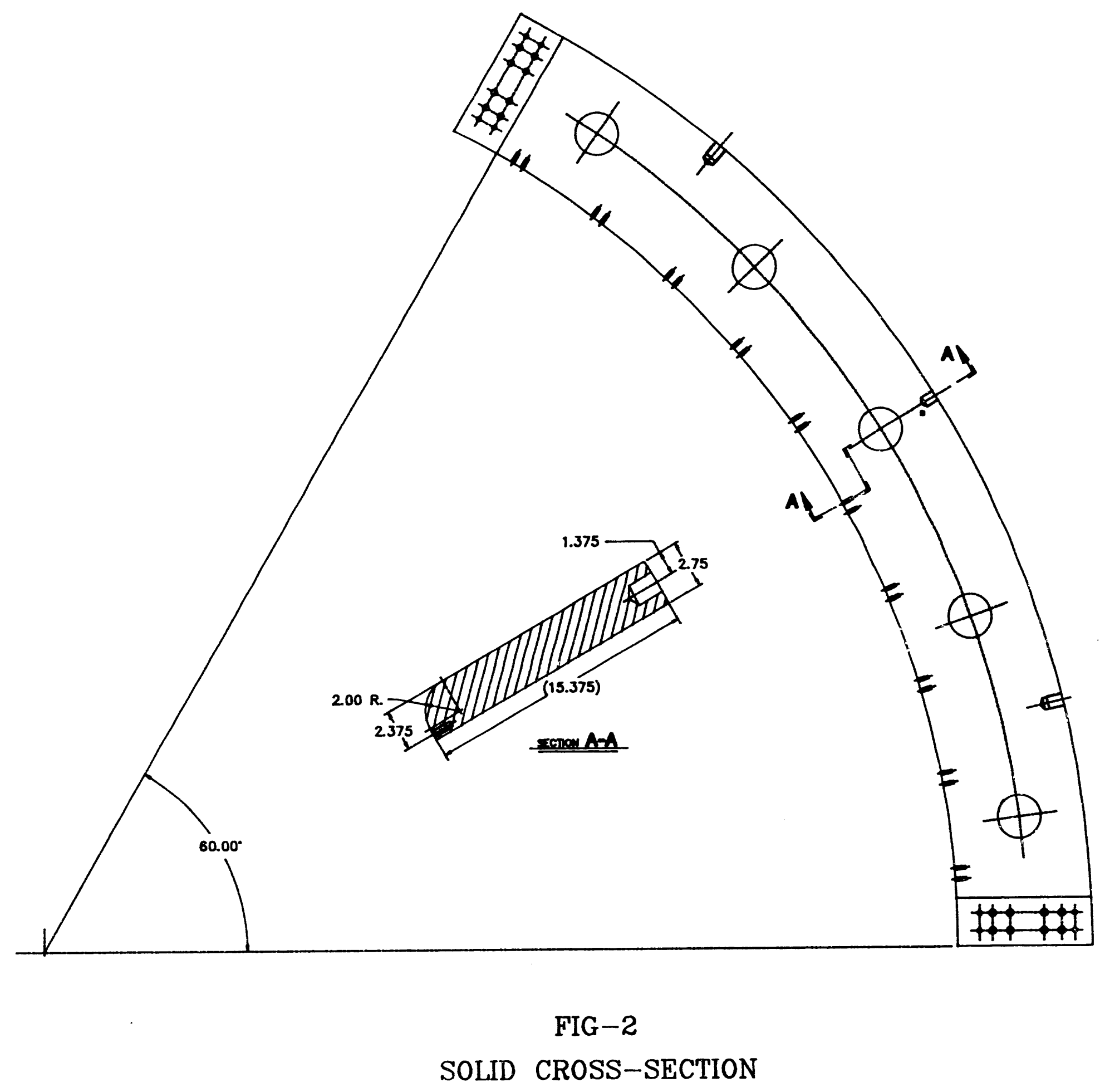




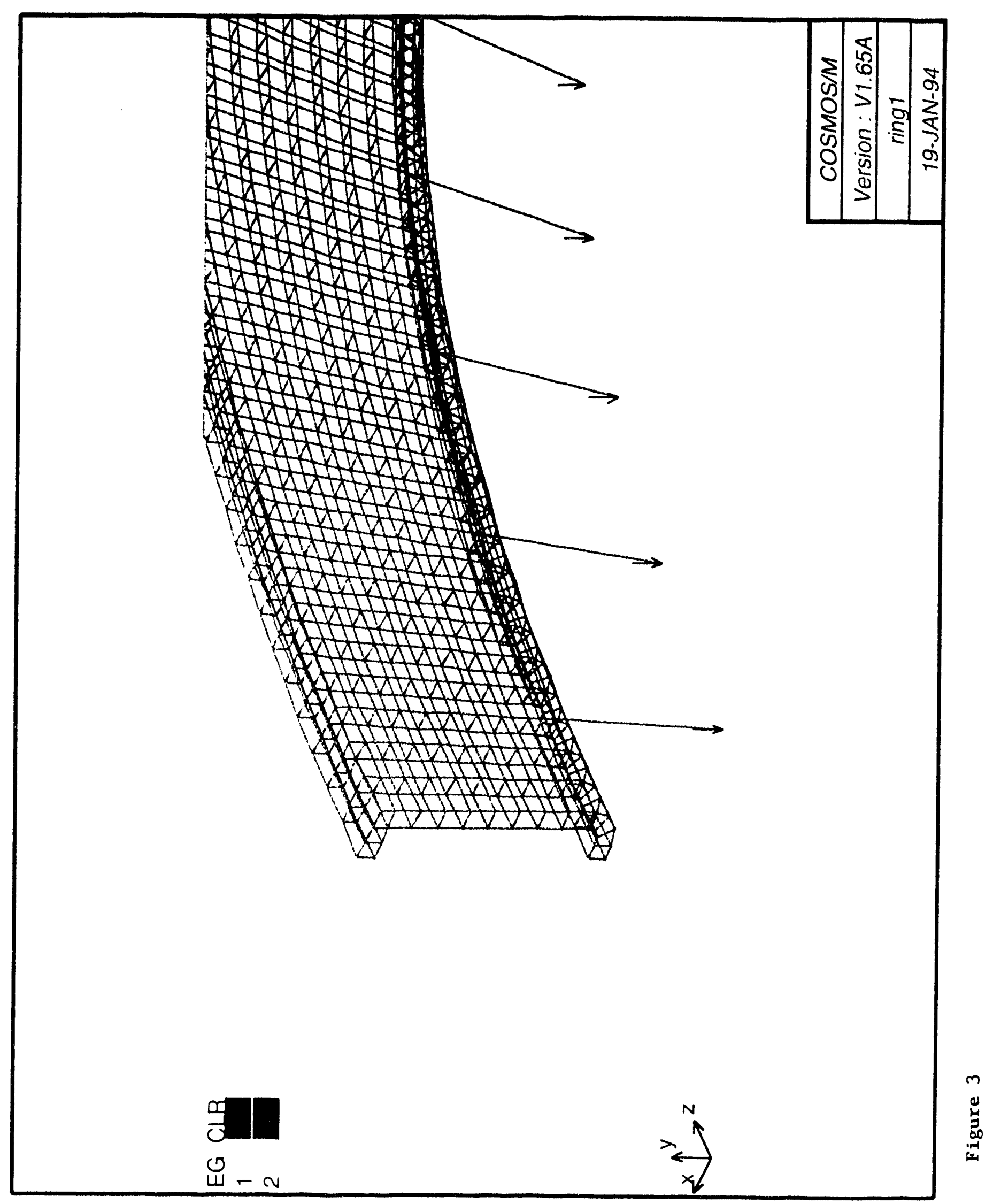



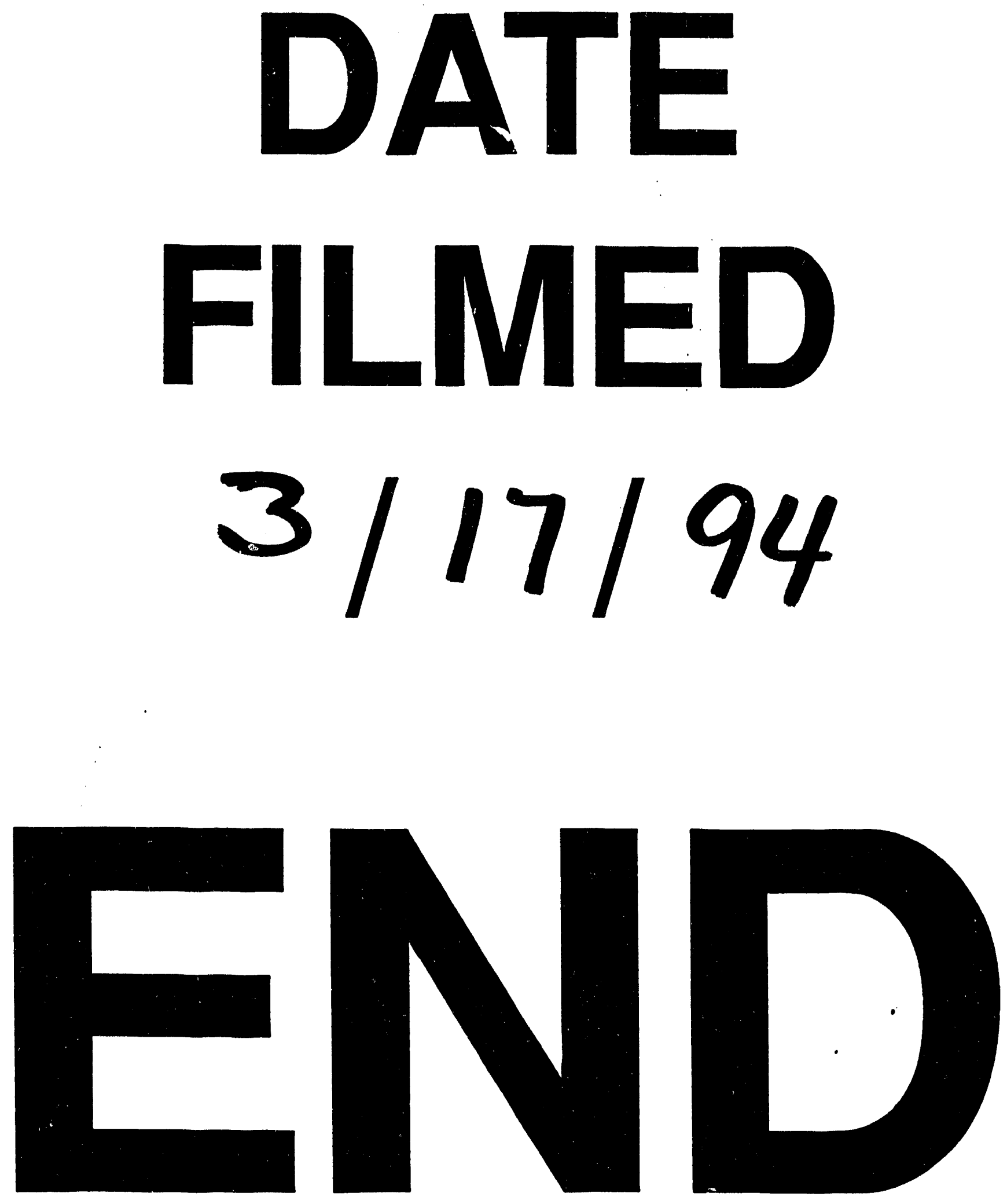
$\mid$ 